\title{
Assessing High- and Low-Temperature Properties of Asphalt Pavements Incorporating Waste Oil Shale as an Alternative Material in Jilin Province, China
}

\author{
Yongchun Cheng ${ }^{1}$, Wensheng Wang ${ }^{1(1)}$, Guojin Tan ${ }^{1, *}$ (1) and Chenglin Shi ${ }^{2}$ (D) \\ 1 College of Transportation, Jilin University, Changchun 130025, China; chengyc@jlu.edu.cn (Y.C.); \\ wangws17@mails.jlu.edu.cn (W.W.) \\ 2 Scientific Research and Development Center, Jilin Provincial Transport Scientific Research Institute, \\ Changchun 130022, China; wangws1991@163.com \\ * Correspondence: tgj@jlu.edu.cn; Tel.: +86-0431-8509-5446
}

Received: 31 May 2018; Accepted: 25 June 2018; Published: 26 June 2018

\begin{abstract}
This study investigates the feasibility of recycling waste oil shale as an alternative material into asphalt pavements in Jilin province, China. The high- and low-temperature properties of asphalt materials play important roles for asphalt pavements in seasonal frozen regions. Laboratory experiments were conducted to analyze the high- and low-temperature properties of asphalt mastics and mixtures. Results indicated that adding oil shale ash (OSA) may lead asphalt to a softer consistency and less temperature susceptibility. Also, OSA could improve high-temperature stability and enhance rutting resistance of asphalt materials, whereas the effect of OSA on low-temperature properties is insignificant by comparison. Moreover, the high- and low-temperature performances of asphalt mixtures were evaluated based on testing roads through rutting depth index, riding quality index, and indirect tensile strength test. It can be proved that the sustainable asphalt materials have better high-temperature stability and rutting resistance and also fulfill the requirements of low-temperature cracking resistance.
\end{abstract}

Keywords: asphalt material; waste oil shale; high-temperature property; low-temperature property

\section{Introduction}

Oil shale reserves in China are estimated as 719.9 billion tons, which can be converted into 47.6 billion tons of shale oil [1]. Moreover, oil shale resources in the three northeast provinces of China account for $47 \%$ compared to the total oil shale resources in China. Among them, Jilin province has the most abundant oil shale resources, accounting for about 30\% with respect to the total oil shale resources in China. Due to the severe energy shortage and rapid development of the economy, oil shale as an alternative and low-cost energy resource has attracted more and more attention. However, a byproduct of the oil shale industry is waste oil shale ash (OSA), which is considered a serious environmental problem and a hazard for human health [2]. The common disposal of waste OSA is land filling, resulting in not only a serious threat for human health and environment but also a barrier for the oil shale industry. The distribution of oil shale resources in China and its development in Jilin province are shown in Figure 1. Regarding this situation, there is a necessity to recycle waste OSA, especially that found in massive landfills. Many methods were tried to reuse OSA wastes in many civil engineering sectors and chemical industries. Today, civil-related studies about wastes recycling have made good progress, and most wastes are used for two essential materials i.e., concrete and asphalt in civil engineering. In this way, waste utilization can also modify the mechanical characteristics and performances of these construction materials. 


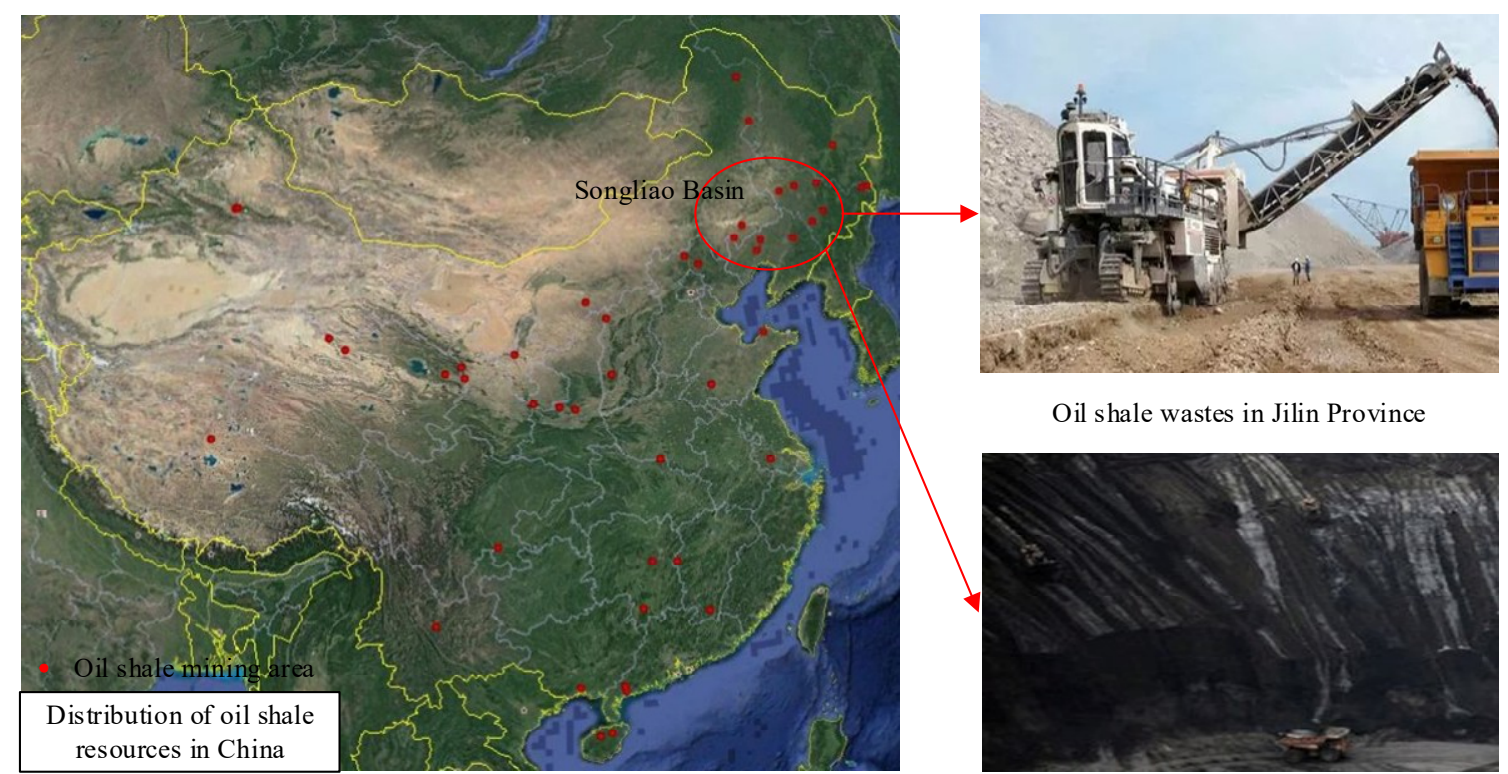

Figure 1. Distribution of oil shale resources in China.

In the construction industry, a large amount of work was conducted to investigate the use of waste ash in concrete. Singh et al. [3] studied the use of coal bottom ash in different replacement levels-20, $30,40,50,75$, and $100 \%$-into two types of concrete mixture with different $28 \mathrm{~d}$ compressive strengths. Test results showed that concrete with coal bottom ash can have a good performance and quality for both types of replaced sand. Bottom ash can replace all sand having a fineness modulus of 1.97 in concrete with a $28 \mathrm{~d}$ compressive strength of $38 \mathrm{MPa}$, and the replacement level is up to $50 \%$ for sand having a fineness modulus of 2.58 in concrete with a $28 \mathrm{~d}$ compressive strength of $34 \mathrm{MPa}$ [3]. Zhen et al. used sewage sludge ash and glass cullet as replacements for natural aggregates and then evaluated the performances of concrete blocks. They observed that the long-term compressive strength of concrete blocks increased, and blocks had the better mechanical and durability performances [4]. Also, some researchers investigated the utilization of oil shale wastes for cement. Test results revealed that OSA could be effectively used in the production of Portland cement $[5,6]$. In addition, there was a standard developed in Estonia with the aim of guiding the utilization of burnt shale [5]. Smadi and Haddad studied the use of OSA as a partial replacement of cement or sand in concrete or mortar. The optimal compressive strength of concrete or mortar can be gained at an OSA replacement of cement, sand, or both of about $10 \%$ by weight. Also, the test results indicated that the compressive strength is not significantly reduced for cement concrete or mortar with OSA up to a replacement ratio of $30 \%$ [6].

Asphalt mixture is the other construction material that has been considered as an appropriate material with the incorporation of waste ash. Zhang et al. [7] used sewage sludge ash to develop an additive for warm mix asphalt, which can produce an asphalt mixture at lower construction temperatures. Arabani et al. [8] conducted a study on asphalt binder modified by rice husk ash with the contents of $5 \%, 10 \%, 15 \%$ and $20 \%$. The results revealed that the rheological properties of asphalt binder can be enhanced by adding rice husk ash. Furthermore, the modification also had more positive impacts on the mechanical properties including Marshall stability, stiffness modulus, rutting strength, and fatigue performance of asphalt mixtures [8]. Similarly, Jeffry et al. [9] evaluated the pavement performances of asphalt mixture containing various contents of nano-charcoal coconut shell ash, i.e., $0 \%$ (control), $1.5 \%, 6 \%$ and $7.5 \%$ through microstructural properties. The results indicated that the engineering properties of the asphalt mixture, such as Marshall stability, dynamic creep etc., were obviously improved when about $6 \%$ nano-charcoal coconut shell ash was added [9]. Considering the environmental, health, and economic issues, the utilization of waste materials can 
be an environment-friendly way to dispose of the aforementioned materials, which could meet the requirements of sustainable development by reducing waste materials [10-12].

A number of researchers have found that OSA can be effectively employed as a practical material in asphalt mixtures. Ghuzlan K et al. [13] used five different ratios of oil shale filler/bitumen varying from 0 to $20 \%$ with an increment of $5 \%$ and evaluated the influences of OSA on high-temperature rheological properties. Then, dynamic shear rheometer (DSR) and viscosity were adopted to study these prepared asphalt binders. Based on their findings, the increase of OSA content to asphalt increased the complex shear modulus, and OSA filler was proved to have a positive effect on asphalt, especially as its high-temperature stability improved [13]. AL-Massaid et al. [14] prepared asphalt mixture samples based on five OSA levels ranging from 0 to $20 \%$ with an increment of $5 \%$ by volume of asphalt. The effect of adding OSA to the asphalt mixtures was evaluated under normal and freeze-thaw conditions. Their results indicated that asphalt mixtures with OSA could improve the normal and freeze-thaw behaviors and the substitution of OSA up to 10\% would improve the performances of asphalt mixture under both conditions [14]. Ibrahim et al. [15] investigated asphalt mixtures with Jordanian OSA at three different percentages, in which OSA was treated as a substitute filler. Besides, they performed the chemical tests to analyze the properties of this type of filler. The findings showed that the mechanical properties and moisture damage of bitumen mix can be enhanced by incorporating OSA, and it was proved that the best performances were achieved through replacing traditional filler by OSA at 10\% [15]. Wahhab et al. [16] blended OSA at a ratio of $2 \%$ with asphalt binder and applied in asphalt concrete mixes, which indicated that modified asphalt binder with OSA significantly improved the performances of the asphalt pavement such as split tensile strength, fatigue life, and resistance to rutting [16]. Azzam et al. [17] studied hot mix asphalt mixtures containing OSA and classical limestone filler based on the Superpave design method. They measured rheological and pavement properties, and observed that hot-mix asphalt incorporating OSA possessed more excellent properties compared to hot-mix asphalt containing ordinary limestone filler [17]. Besides, they investigated hot-mix asphalt pavement with limestone replaced by oil shale filler and made asphalt mixtures at different percentages of oil shale to limestone filler for comparison. The results of this study indicated that the volumetric properties such as air voids and Marshall stability etc. could satisfy the requirements. For example, Marshall stability was improved by 10 to $20 \%$ compared to the all-limestone formulation. OSA also has a positive effect on flexibility in the long-run, and asphalt pavement containing OSA is more fatigue-resistant [18]. These studies showed that waste OSA used as an additive in asphalt materials is feasible and effective. Despite extensive studies that have been conducted about the incorporation of oil shale in asphalt mixtures, the properties of asphalt materials with OSA at high and low temperatures have not been studied systemically.

This paper aims to assess the high- and low-temperature properties of asphalt materials with waste oil shale as an alternative material of mineral powder. Laboratory experiments were carried out to investigate the properties of asphalt mastics and mixtures. The conventional tests, DSR, and bending beam rheometer (BBR) tests were adopted to evaluate the properties of asphalt mastics at high and low temperatures. Also, the performances of asphalt mixture at high and low temperatures were analyzed in terms of the wheel tracking test and low-temperature bending beam test. In addition, with the aim of validating the laboratory experiment results, the asphalt mixtures containing waste OSA were applied to a test road and evaluated by a series of tests.

\section{Raw Materials}

\subsection{Oil Shale Ash}

Generally, there are mainly two methods to utilize oil shale: first, oil shale can be distilled to gain shale oil as well as gas, and second, it can be used for electricity and heat generation through combustion [19]. However, these two methods will produce lots of waste, which leads to environmental pollution. The waste OSAs fall into three categories in accordance with sources, namely power plant 
oil shale ash (PPOSA), size reduction oil shale fly ash (SROSFA), and oil shale semi-coke (OSSC). PPOSA is a residue obtained by burning oil shale, whereas SROSFA is volatile dust particle obtained by burning oil shale. OSSC is a kind of residual wastes produced through a method of retorting oil shale. OSA wastes used in the experiment were collected from Jilin province and were used to prepare asphalt mixtures substituting a conventional filler. The utilization of oil shale and its products are shown in Figure 2, and their geometrical, physical, and chemical properties were also investigated.

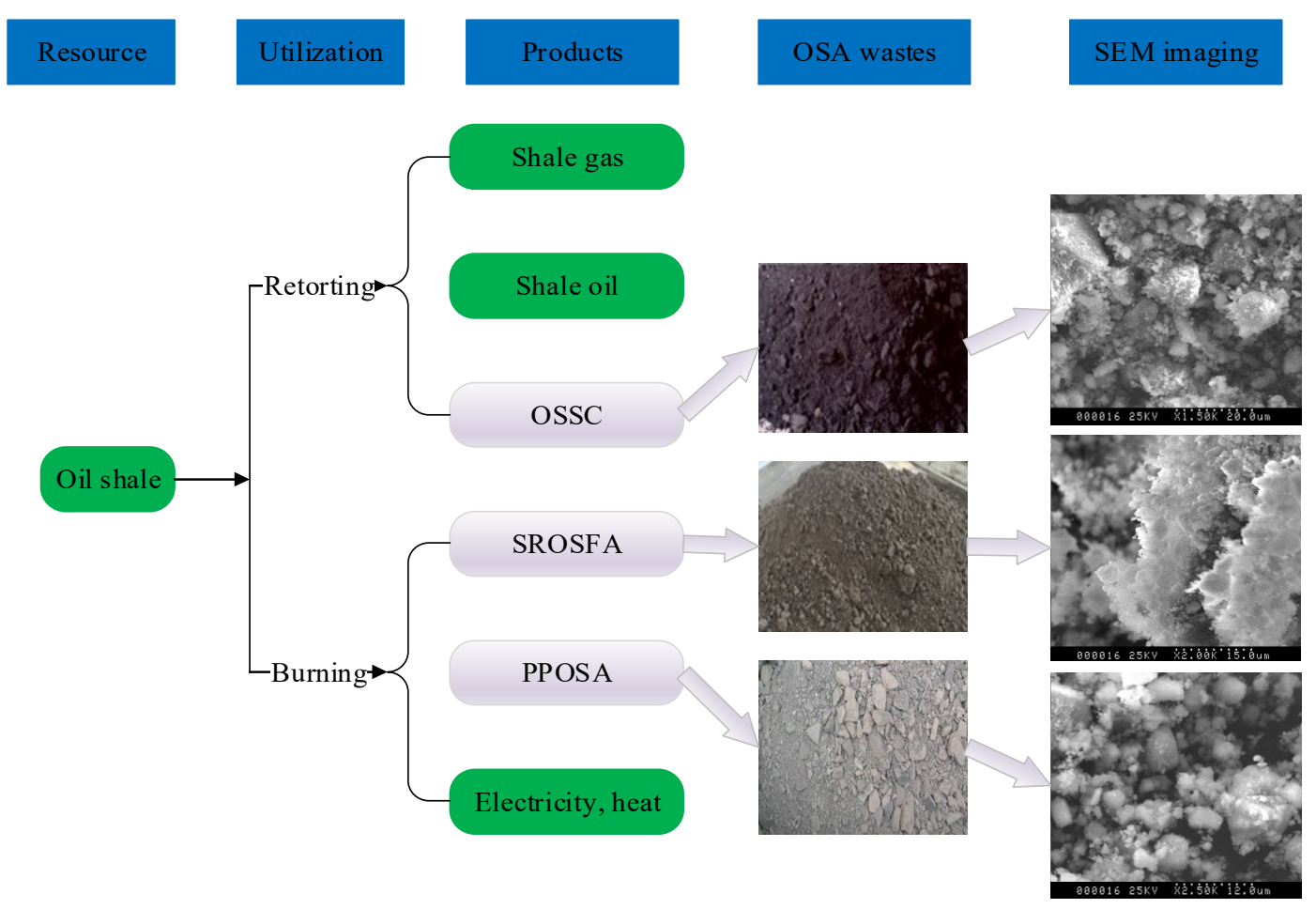

Figure 2. Utilization of oil shale resource and its products.

Scanning electron microscopy (SEM) is widely used for morphology analysis at the microscopic scale. Figure 2 shows the SEM morphology of three OSA wastes, in which it can be seen that the main shape is granulous for PPOSA and OSSC, whereas it is flaky in the case of SROSFA. The particle density was measured by the pycnometer method. Specific surface area (SSA) was measured by the Brunauer-Emmett-Teller $\left(\mathrm{N}_{2}\right.$-BET) adsorption method. Mineral composition analysis by $\mathrm{X}$-ray diffraction (XRD), and elemental and chemical analysis by $\mathrm{X}$-ray fluorescence spectrometry (XRF) were also performed. The corresponding properties are listed in Tables 1-3.

Table 1. Physical properties of three oil shale ash (OSA) wastes.

\begin{tabular}{cccc}
\hline Properties & Main Geometry & Specific Gravity $/ \mathbf{g} / \mathbf{c m}^{3}$ & Specific Surface Area $/ \mathbf{m}^{2} / \mathbf{g}$ \\
\hline PPOSA & Granulous & 2.533 & 5.4486 \\
SROSFA & Flaky & 2.417 & 10.3306 \\
OSSC & Granulous & 2.567 & 16.1940 \\
\hline
\end{tabular}

Table 2. Mineral composition analysis by X-ray diffraction (XRD).

\begin{tabular}{ccc}
\hline Sample & Main Crystalline Phase & Secondary Crystalline Phase \\
\hline PPOSA & Quartz, K-feldspar, Biotite & Illite, Analcime \\
SROSFA & Quartz, K-feldspar & Biotite, Chlorite, Illite, Analcime \\
OSSC & Quartz, K-feldspar & Calcite, Biotite, Chlorite, Illite, Analcime \\
\hline
\end{tabular}


Table 3. Elemental and chemical analysis by X-ray fluorescence spectrometry (XRF).

\begin{tabular}{ccccccccccccc}
\hline Sample & $\mathbf{S i O}_{\mathbf{2}}$ & $\mathbf{A l}_{2} \mathbf{O}_{\mathbf{3}}$ & $\mathbf{F e}_{\mathbf{2}} \mathbf{O}_{\mathbf{3}}$ & $\mathbf{C a O}$ & $\mathbf{M g O}$ & $\mathbf{K}_{\mathbf{2}} \mathbf{O}$ & $\mathbf{N a}_{\mathbf{2}} \mathbf{O}$ & $\mathbf{T i O}_{\mathbf{2}}$ & $\mathbf{P}_{\mathbf{2}} \mathbf{O}_{\mathbf{5}}$ & $\mathbf{M n O}$ & LOI & Total \\
\hline PPOSA & 56.62 & 15.18 & 6.14 & 7.84 & 2.61 & 3.03 & 4.32 & 0.74 & 0.61 & 0.11 & 2.39 & 99.57 \\
SROSFA & 55.82 & 15.10 & 6.32 & 6.16 & 2.91 & 2.89 & 3.86 & 0.72 & 0.45 & 0.11 & 5.39 & 99.73 \\
OSSC & 54.57 & 14.63 & 5.95 & 6.13 & 2.67 & 2.98 & 3.65 & 0.70 & 0.49 & 0.10 & 7.90 & 99.75 \\
\hline
\end{tabular}

\subsection{Asphalt}

The asphalt AH-90 in this experiment was obtained from Panjin in Liaoning province, China, and its physical properties were measured and are given in Table 4.

Table 4. Physical properties of base asphalt.

\begin{tabular}{ccc}
\hline Properties & Measurement & Technical Criterion \\
\hline Penetration $\left(25^{\circ} \mathrm{C}, 100 \mathrm{~g}, 5 \mathrm{~s}\right) / 0.1 \mathrm{~mm}$ & 88 & $80 \sim 100$ \\
Softening point $/{ }^{\circ} \mathrm{C}$ & 47 & $\geq 44$ \\
Ductility $\left(15^{\circ} \mathrm{C}, 5 \mathrm{~cm} / \mathrm{min}\right) / \mathrm{cm}$ & 125 & $\geq 100$ \\
Flash point $/{ }^{\circ} \mathrm{C}$ & 280 & $\geq 245$ \\
Specific gravity $\left(15^{\circ} \mathrm{C}\right) / \mathrm{g} / \mathrm{cm}^{3}$ & 1.012 & - \\
\hline & After TFOT & \pm 0.8 \\
\hline Mass loss $/ \%$ & -0.2 & $\geq 57$ \\
Penetration ratio of $25^{\circ} \mathrm{C} / \%$ & 66 & $\geq 8$ \\
Ductility $\left(10{ }^{\circ} \mathrm{C}\right) / \mathrm{cm}$ & 21 &
\end{tabular}

\subsection{Aggregates and Filler}

Coarse and fine aggregates as well as filler passing through a $0.075 \mathrm{~mm}$ sieve were obtained from a local mine in Fusong country of Jilin province, China, and Table 5 shows their physical properties.

Table 5. Physical properties of aggregates and filler.

\begin{tabular}{|c|c|c|c|c|c|c|c|}
\hline \multirow{2}{*}{ Properties } & \multicolumn{5}{|c|}{ Coarse Aggregate } & \multirow{2}{*}{$\begin{array}{c}\text { Fine Aggregate } \\
2.36 \sim 0.075 \mathrm{~mm}\end{array}$} & \multirow{2}{*}{$\begin{array}{c}\text { Mineral Powder } \\
\leq 0.075 \mathrm{~mm} \\
\end{array}$} \\
\hline & $19 \mathrm{~mm}$ & $13.2 \mathrm{~mm}$ & $9.5 \mathrm{~mm}$ & $4.75 \mathrm{~mm}$ & $2.36 \mathrm{~mm}$ & & \\
\hline Aggregate crushing/\% & & & 17.6 & & & - & - \\
\hline Water absorption/\% & 0.38 & 0.49 & 0.66 & 1.43 & 1.62 & - & - \\
\hline Flakiness index/\% & 6.9 & 6.7 & 7.7 & 8.2 & 7.4 & - & - \\
\hline Sand equivalent & - & - & - & - & - & $89(\geq 60)$ & - \\
\hline
\end{tabular}

\section{High- and Low-Temperature Performances of Asphalt Materials in Laboratory}

\subsection{Analysis of High-and Low-Temperature Properties for Asphalt Mastics}

Considering practical engineering, the filler and asphalt contents in an asphalt mixture are roughly equal, and their proportions account for approximately $4.5 \%$ of aggregates by weight. Thus, this paper investigated modified asphalt mastics with a filler to asphalt ratio of 1.0. Three kinds of crushed or powdered OSA fillers were obtained for asphalt mastic. At the fixed filler to asphalt ratio of 1.0, conventional mineral powder was replaced with OSA by $0 \%, 10 \%, 20 \%$, and $30 \%$ by volume, and the fillers with different OSA/MP ratios were mixed with AH-90 base asphalt. The detailed preparation procedures are (i) the base asphalt AH-90, mineral powder and three kinds of OSA filler were heated in order to ensure that asphalt could flow fully and (ii) the mineral and OSA fillers were mixed with base bitumen, and then this mix was stirred to prepare asphalt mastics using a high-speed shear homogenizer until the fillers were distributed uniformly in asphalt mastic. 


\subsubsection{Penetration, Softening Point, and Ductility Tests}

Penetration is the most common parameter to stand for the consistency of bituminous materials. Penetration value is expressed in basic unit of $0.1 \mathrm{~mm}$ that a needle weighing about $100 \mathrm{~g}$ vertically drops into the asphalt specimen in five seconds. According to ASTM D5 [20], a penetration test was carried out through a penetration apparatus at test temperature of $25^{\circ} \mathrm{C}$. A larger penetration usually represents a softer consistency. Thus, the asphalt with a larger penetration is generally preferred in cold climates, and asphalt with smaller penetration is often used in hot climate areas.

Softening point is defined as the temperature when asphalt cannot hold a $3.5 \mathrm{~g}$ steel ball. The ring and ball apparatus can be adopted for determining the softening point of asphalt, and the heating speed was set as $5{ }^{\circ} \mathrm{C} / \mathrm{min}$ according to ASTM D36 [21]. In general, the softening point relates to the temperature susceptibility of bituminous materials, and a larger value softening point stands for less temperature susceptibility. Therefore, the asphalt with a higher softening point is preferred in warmer places.

The measured data from the penetration and softening point tests were collected for calculating penetration index $(P I)$, which can indicate a quantitative index for bitumen responding to temperature. Based on the previously measured softening point as well as penetration, the value of PI can be calculated.

$$
P I=\left[1952-500 \times\left(\log _{10} P 25\right)-20 \times S P\right] /\left[50 \times\left(\log _{10} P 25\right)-S P-120\right],
$$

where $P 25$ represents the penetration value at the temperature of $25{ }^{\circ} \mathrm{C}$ and $S P$ stands for softening point. A higher PI value generally indicates lower temperature susceptibility [22].

A ductility test is carried out through stretching the asphalt to its breaking point under given conditions. According to ASTM D113 [23], ductility used in the experiment was obtained at the test temperature of $15^{\circ} \mathrm{C}$, and the stretching rate was $5 \mathrm{~cm}$ per minute.

Three replicate samples were used to complete the penetration and ductility tests of each type of asphalt mastic, and two replicate samples were prepared for the softening point test. As shown in Figure 3, the effects of OSA content for different filler types on penetration, softening point, penetration index, and ductility are illustrated for asphalt mastics. Results indicate that the softening point, penetration index, and ductility first increase within OSA/MP ratio of $20 \%$ and then decrease when the OSA/MP ratio exceeds $20 \%$. As for penetration, the results fluctuate up and down but reach higher values near an OSA/MP ratio of $20 \%$. In summary, with respect to asphalt mastics, the penetration, softening point, penetration index, and ductility are enhanced by the addition of OSA wastes according to the above results, indicating softer consistency, less temperature susceptibility, better anti-deformation ability, and less cracking for seasonal frozen regions.

Thus, in view of the influence trends, the OSA/MP ratio of modified asphalt mastics can be recommended as $20 \%$. The selected OSA/MP ratio is further investigated for its effectiveness in modifying asphalt performance including DSR and BBR tests, and AH-90 base asphalt was also tested as a control. 


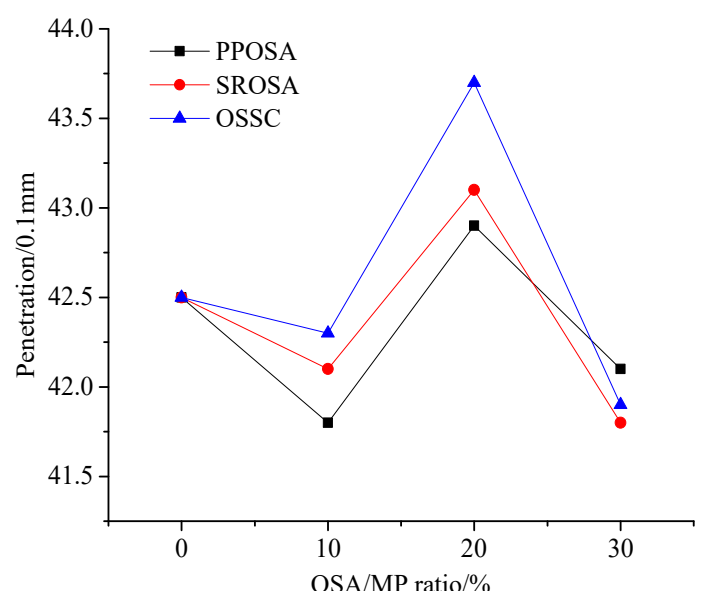

(a)

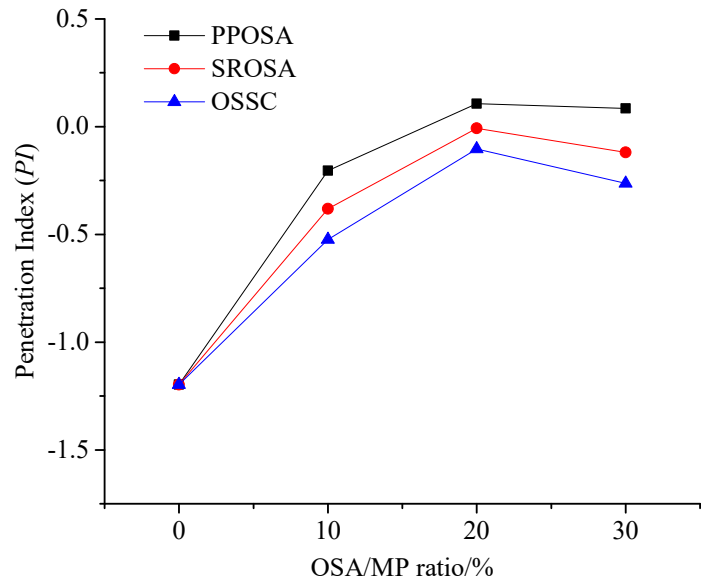

(c)

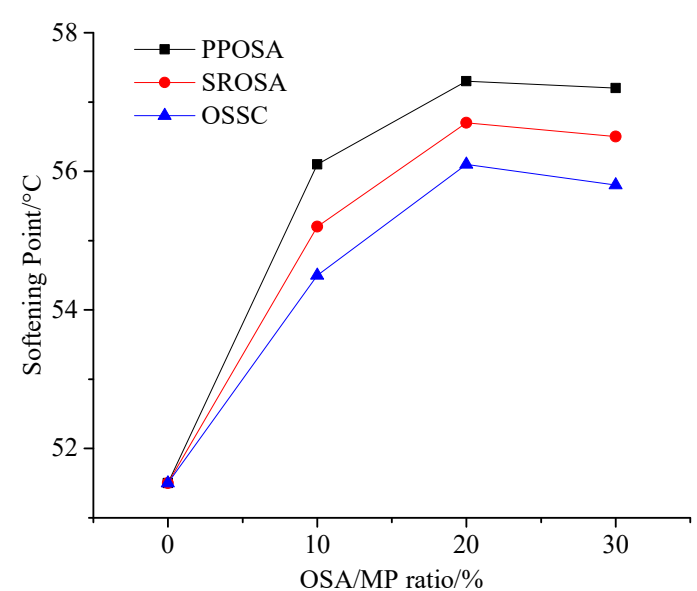

(b)

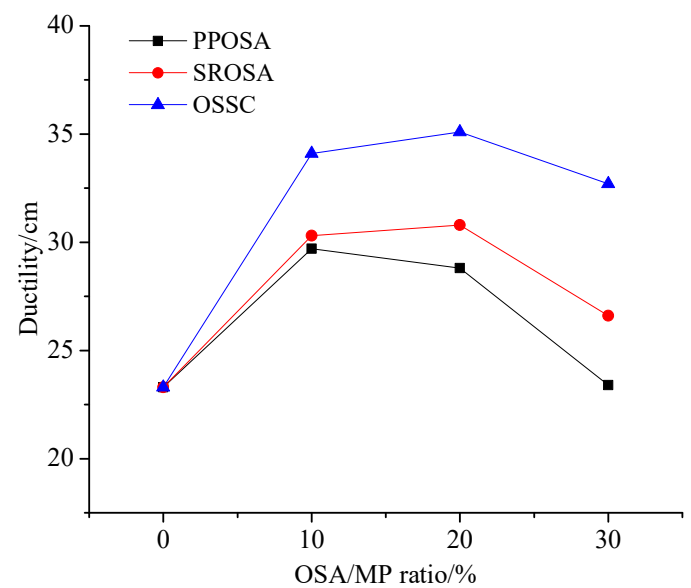

(d)

Figure 3. Penetration, softening point, penetration index, and ductility test results. (a) Penetration test results; (b) Softening point test results; (c) Penetration index results; (d) Ductility test results.

\subsubsection{DSR Test for High-Temperature and Intermediate-Temperature Performance}

The dynamic shear rheometer (DSR) test is utilized to characterize the high-temperature behavior of bitumen, which was first proposed by the strategic highway research program (SHRP) [24]. This test defines two rheological indices, i.e., complex shear modulus $\left(G^{*}\right)$ and phase angle $(\delta)$ for resistance to deformation as well as lag between shear stress and shear strain. Then, a rutting factor $\left(G^{*} / \sin \delta\right)$ can be calculated. With the aim of resisting wheel rutting, asphalt mastic should be stiff to not deform too much but should also be elastic. In this paper, the rheological parameters were measured by Bohlin DSR (Malvern Instruments Limited, UK), and the test was conducted at constant strain mode with $10 \mathrm{rad} / \mathrm{s}$ according to ASTM D7175 [25]. Behnood and Olek [26] studied the properties of modified asphalt binders at a wide range of service climate conditions and used DSR to evaluate the high-temperature and intermediate-temperature properties of binders [26,27]. Considering that there are many more intermediate-temperature days than high-temperature days in the seasonal frozen region, the test temperatures ranged from $30^{\circ} \mathrm{C}$ to $60^{\circ} \mathrm{C}$, including high temperature and intermediate temperature.

Two replicate samples were prepared and tested in the DSR tests. Test results of $G^{*}, \delta$, and highand intermediate-temperature properties, i.e., $G^{*} \sin \delta$ and $G^{*} / \sin \delta$, are shown in Figure 4. As shown in Figure $4 \mathrm{a}$, it can be observed that, with regard to all asphalt mastics, complex shear modulus $\left(G^{*}\right)$ decreases with increased temperature, but phase angle $(\delta)$ shows an increasing trend. Meanwhile, there is obvious differences of $G^{*}$ and $\delta$ results among asphalt mastics with different OSA filler and mineral powder content. For $G^{*}$, OSSC > SROSFA > PPOSA > MP, and it is just the opposite 
for $\delta$. The values of $G^{*} \sin \delta$ and $G^{*} / \sin \delta$ can be calculated for characterizing fatigue and rutting resistances. Compared with the base asphalt mastic with MP, the values of $G^{*} / \sin \delta$ increase for all asphalt mastics containing OSA at temperatures ranging from $50{ }^{\circ} \mathrm{C}$ to $60^{\circ} \mathrm{C}$. The high-temperature stability of the asphalt mastic with OSSC is the largest among these asphalt mastics, followed by the asphalt mastics with SROSFA, PPOSA, and MP. These observations show that OSA can have a positive effect on the rheological performance of asphalt, and their rutting resistance was enhanced compared to the base asphalt containing MP. In addition, Figure $4 \mathrm{~b}$ presents the average test results of intermediate-temperature properties $\left(G^{*} \sin \delta\right)$ in the temperature range of $30^{\circ} \mathrm{C}$ to $40^{\circ} \mathrm{C}$. It can be seen that the test results of the four asphalt mastics are relatively close to each other, which indicates that the effect of OSA on the intermediate temperature properties of asphalt mastics is negligible.

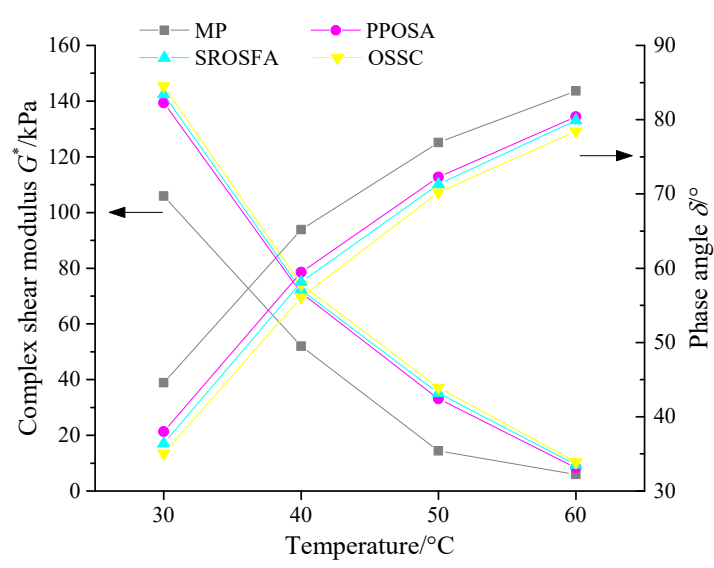

(a)

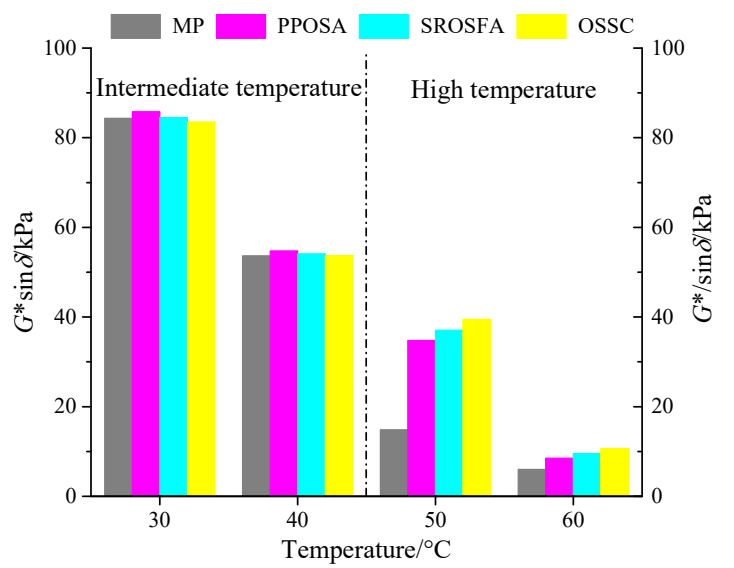

(b)

Figure 4. Dynamic shear rheometer (DSR) tests at different temperatures. (a) Dynamic shear test results; (b) High and intermediate temperature properties.

\subsubsection{BBR Test for Low-Temperature Performance}

The bending beam rheometer (BBR) test is widely used to evaluate low-temperature properties for bitumen. In the BBR test, according to AASHTO T313 [28], two replicate asphalt beam samples were first prepared. The dimensions of the beam samples were $6.25 \times 12.5 \times 127 \mathrm{~mm}$. They were placed at the test temperature for $60 \mathrm{~min}$ before testing. Then a load of $0.98 \mathrm{~N}$ was acted on the center of a simply supported asphalt beam sample in water bath at the given temperature. Besides, low-temperature creep performances of asphalt mastics were recorded at three different test temperatures of $-6{ }^{\circ} \mathrm{C},-9{ }^{\circ} \mathrm{C}$, and $-12{ }^{\circ} \mathrm{C}$. Through the deflection versus loading time at $8,15,30$, 60,120 , and $240 \mathrm{~s}$, two important low-temperature indices, i.e., creep stiffness $(S)$ and changing rate of creep stiffness ( $m$-value), were calculated to assess the resistance to low-temperature cracking for asphalt [29]. The values of creep stiffness $S$ and creep rate $m$ are shown in Figure 5. 


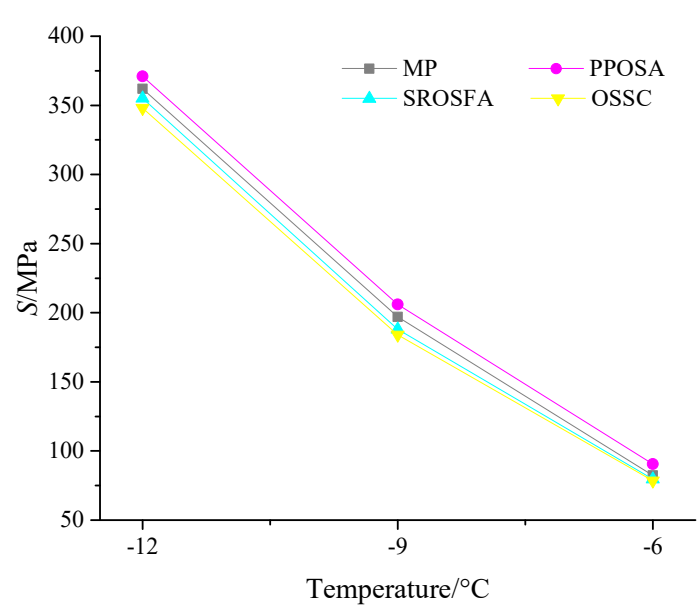

(a)

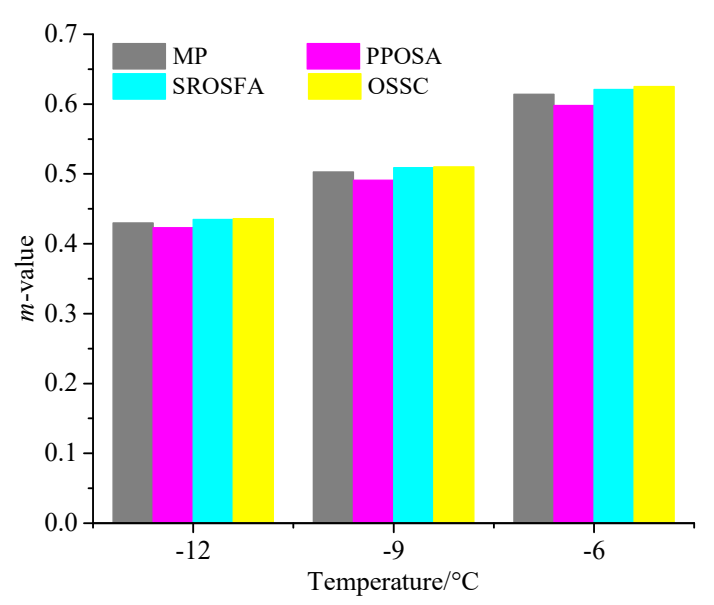

(b)

Figure 5. Bending beam rheometer (BBR) test results of asphalt mastics. (a) Creep stiffness $S$ results; (b) $m$-value results.

As demonstrated in Figure 5, the creep stiffness $S$ values of the modified asphalt mastics except PPOSA are slightly lower than that of the asphalt mastic with MP, while the $m$ values of the modified asphalt mastics except PPOSA slightly increase compared with the asphalt mastic with MP. Generally, a smaller value of creep stiffness $S$ indicates a larger creep deformation and that the asphalt samples have a good low-temperature flexibility. As for the changing rate of stiffness $m$-value, it is considered to be related to the stress recovery and crack resistance at lower temperatures. The observations indicate that adding SROSFA and OSSC leads the $S$ and $m$ values to change insignificantly compared to the base asphalt mastic containing MP; hence, the effect of OSA fillers on the cryogenic flexibility of asphalt mastics is insignificant.

\subsection{Analysis of High- and Low-Temperature Properties for Asphalt Mixtures}

In this paper, several types of hot mix asphalt (HMA) were designed and prepared in accordance with [30]. HMA mixtures including traditional dense-graded asphalt mixture (AC), stone mastic asphalt (SMA), and asphalt-treated base (ATB) are the most common mixture type in China. AC is a well-graded mixture and is used extensively for all pavement layers and for all traffic conditions in China. SMA is a gap-graded HMA originally developed in Europe to maximize rutting resistance and durability. In general, due to more asphalt, better aggregates, and some modifications, the cost of SMA is larger compared to AC. As for ATB, this type of HMA is the least expensive among these three types of HMA because ATB requires less asphalt and the aggregates used are not good as those in SMA and AC.

The selected aggregate gradations used for AC-20, SMA-16, and ATB-25 mixtures in this study are listed in Table 6 . Asphalt mixtures were prepared through partially replacing $20 \%$ mineral powder by three types of OSA filler (PPOSA, SROSFA, and OSSC by volume) with the same coarse and fine aggregates. In the mixture preparation, waste oil shales were crushed and ground in advance, which satisfies the requirement of filler size. The Standard Marshall design procedure was employed to design asphalt mixtures, and the preparation procedure is described as follows:

(i) Aggregates, mineral powder, and OSA fillers were weighed and placed in the oven at $180{ }^{\circ} \mathrm{C}$ for two hours following the aggregate gradation, and the asphalt was heated to $150^{\circ} \mathrm{C}$ in accordance with the viscosity requirement.

(ii) Coarse and fine aggregates as well as asphalt were poured into the mixing pot and blended together at $165^{\circ} \mathrm{C}$ and a mixing speed of $80 \mathrm{r} / \mathrm{min}$ for $1.5 \mathrm{~min}$ until all aggregates were coated. 
(iii) The weighted fillers including mineral powder and OSA fillers were added and mixed well at $165^{\circ} \mathrm{C}$ and a mixing speed of $80 \mathrm{r} / \mathrm{min}$ using the mixing pot for $1.5 \mathrm{~min}$.

(iv) asphalt mixtures were compacted with 75 blows per side for AC-20 and ATB-25 and 50 blows per side for SMA-16. The Marshall cylindrical specimens with $63.5 \pm 1.3 \mathrm{~mm}$ height and $101.6 \pm 0.2 \mathrm{~mm}$ diameter were prepared using the Marshall hammer method.

The optimum asphalt contents (OAC) of different mixture types, i.e., AC-20, SMA-16 and ATB-25 were determined at the maximum Marshall stability, maximum density, and median air void by using the Marshall test method [31]. Here, it should be noted that OAC is the asphalt to aggregates ratio by weight, and the asphalt mixtures with conventional mineral filler, PPOSA, SROSFA and OSSC are abbreviated as MP-AM, PPOSA-AM, SROSFA-AM, and OSSC-AM, respectively. The corresponding OAC results were $4.43 \%$ (MP-AM), 4.73\% (PPOSA-AM), 4.6\% (SROSFA-AM), and 4.55\% (OSSC-AM) for AC-20; 6.41\% (MP-AM), 6.81\% (PPOSA-AM), 6.66\% (SROSFA-AM), and 6.50\% (OSSC-AM) for SMA-16; 3.92\% (MP-AM), 4.21\% (PPOSA-AM), 4.11\% (SROSFA-AM); and 4.06\% (OSSC-AM) for ATB-25, respectively.

Table 6. Aggregate gradation of AC-20, SMA-16, and ATB-25.

\begin{tabular}{cccccccccccccc}
\hline Sieve/mm & $\mathbf{3 1 . 5}$ & $\mathbf{2 6 . 5}$ & $\mathbf{1 9}$ & $\mathbf{1 6}$ & $\mathbf{1 3 . 2}$ & $\mathbf{9 . 5}$ & $\mathbf{4 . 7 5}$ & $\mathbf{2 . 3 6}$ & $\mathbf{1 . 1 8}$ & $\mathbf{0 . 6}$ & $\mathbf{0 . 3}$ & $\mathbf{0 . 1 5}$ & $\mathbf{0 . 0 7 5}$ \\
\hline AC-20 & - & 100 & 98.9 & 87.8 & 76.3 & 65.3 & 43.4 & 25.2 & 19 & 13.7 & 9.6 & 8.2 & 6.4 \\
SMA-16 & - & - & 100 & 96.3 & 73.1 & 47.7 & 28.7 & 20.1 & 16.5 & 13.8 & 12 & 11.5 & 10.1 \\
ATB-25 & 100 & 99.8 & 72.6 & 59.2 & 52.2 & 45.2 & 31.1 & 18.6 & 14.7 & 11.4 & 8.4 & 7.3 & 5.4 \\
\hline
\end{tabular}

\subsubsection{High-Temperature Dynamic Stability Test}

The wheel tracking test was conducted on three types of HMA with different fillers to evaluate their high-temperature properties according to JTG E20-2011 [32]. The square slab specimens with a length and width $300 \mathrm{~mm}$ and thickness $50 \mathrm{~mm}$ were prepared and placed in a dry condition at $60{ }^{\circ} \mathrm{C}$ for $6 \mathrm{~h}$. Then, a solid rubber tire was applied on the specimen for $60 \mathrm{~min}$ with $42 \mathrm{cycle} / \mathrm{min}$, in which the tire had a constant pressure of $0.7 \mathrm{MPa}$. The displacement of the specimen in the vertical direction was obtained by linear variable differential transformer (LVDT), and the rutting deflection was recorded per $20 \mathrm{~s}$ [33].

Dynamic stability is determined through dividing (60-45) $\mathrm{min} \times 42$ cycle/min by the rutting deflection variable between $60 \mathrm{~min}$ and $45 \mathrm{~min}$. Three replicate specimens were used for the dynamic stability test of each type of asphalt mixture, and the dynamic stability results regarding the high-temperature rutting performance of the asphalt mixtures. It can be observed in Figure 6 that after partially replacingmineral powder by OSA, the dynamic stability of the asphalt mixtures increased in varying degrees. Besides, the dynamic stability values of these three types of HMA with different fillers are acceptable above the criterion $(800 \mathrm{cycle} / \mathrm{mm}$ for AC and ATB, $1500 \mathrm{cycle} / \mathrm{mm}$ for SMA). A higher dynamic stability value is more attractive for the resistance to wheel rutting, so the high-temperature stability performance of asphalt mixture was improved by the addition of OSA, which is also reflected in the asphalt mastics, as mentioned in Figure 4. In addition, the results of one-way analysis of variance (ANOVA) using SPSS software for the dynamic stability test are listed in Table 7. From Table 7, the F-values of PPOSA-AM are lower and the corresponding $p$-values are larger than 0.05 except SMA, while the $p$-values of SROSFA-AM and OSSC-AM are basically lower than 0.01. It could be concluded that PPOSA has insignificant influence on the high-temperature dynamic stability of asphalt mixture with MP for AC and ATB. SROSFA and OSSC present a significant influence on the asphalt mixture for AC, SMA, and ATB. 


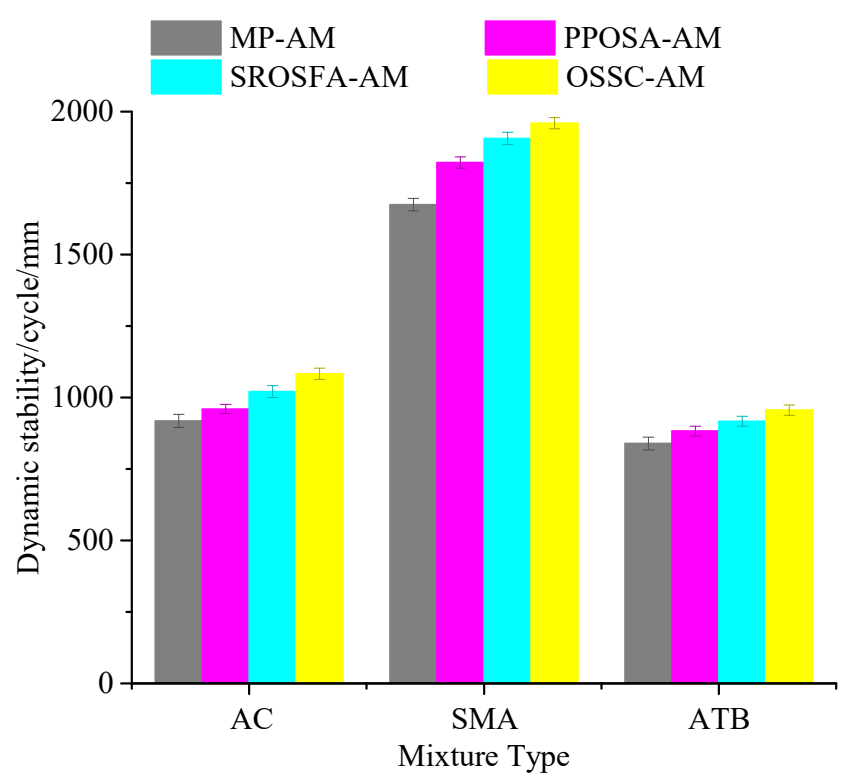

Figure 6. Dynamic stability test results.

Table 7. One-way analysis of variance (ANOVA) for dynamic stability results.

\begin{tabular}{ccccc}
\hline Mixture Type & Sources & F-Value & $p$-Value & Significance \\
\hline \multirow{2}{*}{ AC } & PPOSA-AM vs. MP-AM & 4.638 & 0.098 & - \\
& SROSFA-AM vs. MP-AM & 22.637 & 0.009 & $* *$ \\
& OSSC-AM vs. MP-AM & 61.781 & 0.001 & $*$ \\
\hline \multirow{2}{*}{ SMA } & PPOSA-AM vs. MP-AM & 50.982 & 0.002 & $* *$ \\
& SROSFA-AM vs. MP-AM & 114.078 & $<0.001$ & $*$ \\
& OSSC-AM vs. MP-AM & 193.906 & $<0.001$ & $*$ \\
\hline \multirow{2}{*}{ ATB } & PPOSA-AM vs. MP-AM & 4.875 & 0.092 & - \\
& SROSFA-AM vs. MP-AM & 14.890 & 0.018 & $*$ \\
& OSSC-AM vs. MP-AM & 33.765 & 0.004 & $*$ \\
\hline
\end{tabular}

Note: "-" indicates insignificant correlation; “*” is significant at the 0.05 level. " ***" is significant at the 0.01 level.

\subsubsection{Low-Temperature Cracking Resistance Test}

Low-temperature bending beam tests were carried out at $-10^{\circ} \mathrm{C}$, and the acted loading and corresponding vertical deflection were recorded by sensor and LVDT. Three replicate samples were prepared for the low-temperature cracking resistance test and the flexural-tensile failure strain results are shown in Figure 7. 


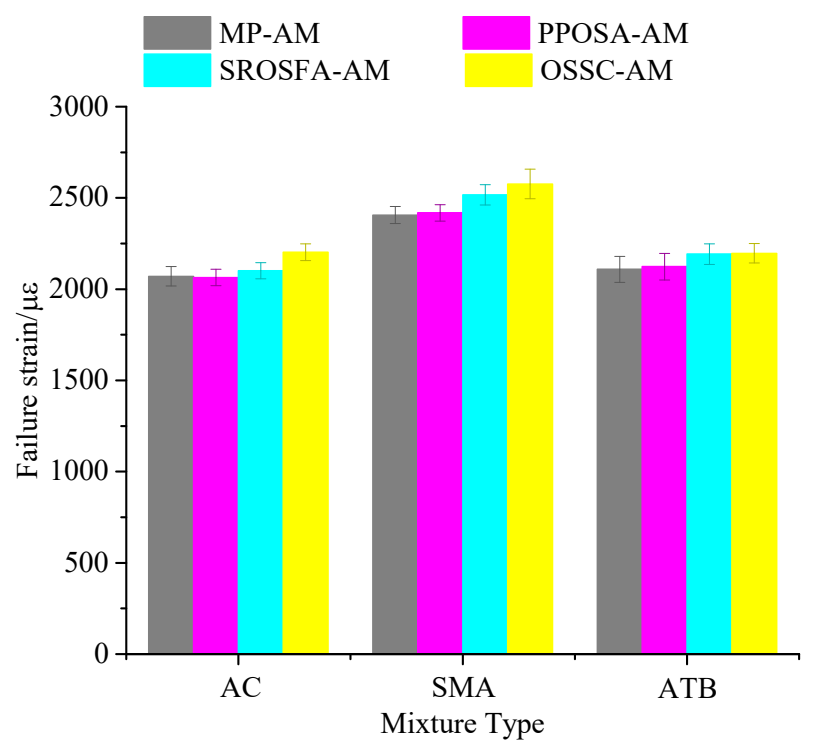

Figure 7. Flexural-tensile failure strain results.

As plotted in Figure 7, when OSA was used to partially replacemineral powder, the flexural strain results of asphalt mixture are higher than the criterion, meeting the requirements of the Chinese standard specification. However, due to the larger standard deviations, the low-temperature performance implied from the flexural-tensile failure strain results may have an unclear trend. Consequently, the asphalt mixtures containing OSA fillers can fulfill the requirements of low-temperature performance, and OSA fillers were proved to have no negative influence on asphalt mixtures compared to ordinary mineral powder. In order to validate credibility, the statistical analysis was conducted, and the one-way ANOVA results are listed in Table 8. It is observed that all $F$-values are lower and the corresponding $p$-values are larger than 0.05 , which indicates that PPOSA, SROSFA, and OSSC present insignificant influences on the low-temperature cracking resistance of asphalt mixture with MP for these three asphalt mixture types.

Table 8. One-way analysis of variance (ANOVA) for flexural-tensile failure strain results.

\begin{tabular}{ccccc}
\hline Mixture Type & Sources & F-Value & $\boldsymbol{p}$-Value & Significance \\
\hline \multirow{2}{*}{ AC } & PPOSA-AM vs. MP-AM & 0.017 & 0.903 & - \\
& SROSFA-AM vs. MP-AM & 0.405 & 0.559 & - \\
& OSSC-AM vs. MP-AM & 7.103 & 0.056 & - \\
\hline \multirow{2}{*}{ SMA } & PPOSA-AM vs. MP-AM & 0.070 & 0.805 & - \\
& SROSFA-AM vs. MP-AM & 4.713 & 0.096 & - \\
\hline \multirow{3}{*}{ ATB } & OSSC-AM vs. MP-AM & 6.646 & 0.061 & - \\
& PPOSA-AM vs. MP-AM & 0.039 & 0.852 & - \\
& SROSFA-AM vs. MP-AM & 1.688 & 0.264 & - \\
\hline
\end{tabular}

Note: "-" indicates insignificant correlation.

\section{High- and Low-Temperature Properties of Asphalt Pavements on Testing Road}

\subsection{Testing Road}

Figure 8 shows the normal and testing asphalt pavements of He-Da highway, in which the filler type in testing asphalt pavement is OSSC. After completing the pavement construction, the basic performances were conducted for the check and acceptance of quality. Compaction is a key index in 
controlling road stability during pavement construction. Besides, asphalt content is also important for the quality of pavement construction. After testing, the average compaction can reach above $96 \%$, and the asphalt content is about $4.40 \%$ i.e., the asphalt-aggregate ratio is about $4.60 \%$. Test results show that all tested performances for the testing road can fulfill the Chinese standard specification, which indicates the good construction quality.

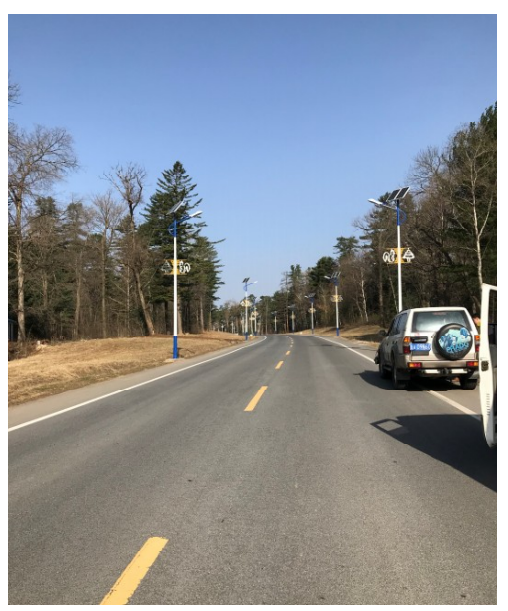

(a)

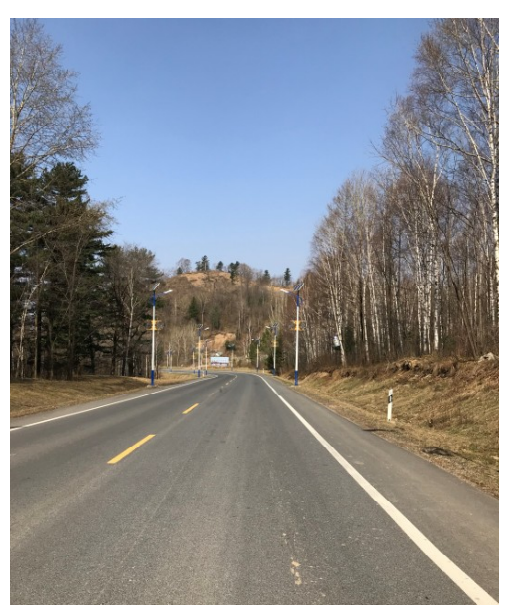

(b)

Figure 8. Observations of normal and testing roads. (a) Normal asphalt pavement; (b) Testing asphalt pavement.

\subsection{Performances of Testing Road}

After more than one year, specimens were cored from the normal and testing roads in the same section of He-Da highway to validate the test results in the laboratory. Pavement rutting is one of major asphalt pavement distresses, which not only relates with driving comfort but also results in pavement premature failure. In addition, pavement roughness is often used to evaluate the driving comfort. Thus, rutting depth index and riding quality index are selected to quantify the rutting and roughness levels of asphalt pavement [34]. The rutting depth index and riding quality index tests were conducted using an automatic pavement rutting evaluation system, and response-type pavement roughness evaluation system (Shanghai Pres Highway and Traffic Technology Inc., Shanghai, China), respectively. The testing vehicle and a cored cylindrical specimen are shown in Figure 9. During the test, the segmental spacing was set as $20 \mathrm{~m}$, and the average speed of testing vehicle was about $50 \mathrm{~km} / \mathrm{h}$, in which normal road was tested for about $2 \mathrm{~km}$ and testing road was tested for $5 \mathrm{~km}$. For convenient comparison, the testing results were chosen per $100 \mathrm{~m}$ and the asphalt road with length $1 \mathrm{~km}$ was selected for normal and testing roads, respectively. Table 9 lists the rutting depth index and riding quality index results. With regard to evaluating grade, grades "very good," "good," "medium," "poor," and "very poor" corresponds to ">90," "80 90," "70 80," “60 70," and "<60," respectively. 


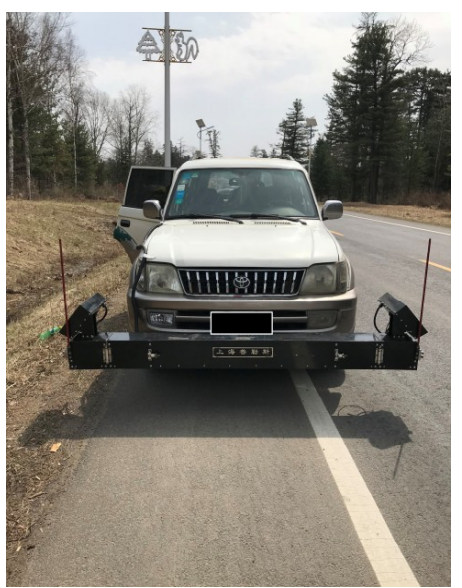

(a)

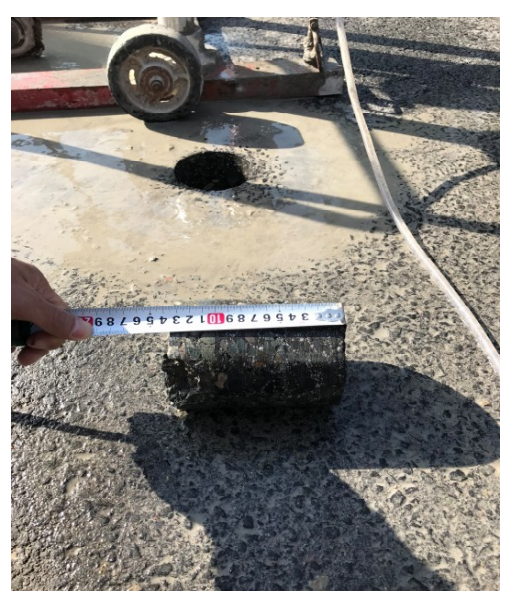

(b)

Figure 9. Field testing and coring. (a) Testing vehicle; (b) Field coring for cylindrical specimen.

Table 9. Rutting depth index and riding quality index results.

\begin{tabular}{lcccccccccccc}
\hline \multicolumn{1}{c}{ Indices } & Road Type & $\mathbf{1 0 0} \mathbf{~}$ & $\mathbf{2 0 0} \mathbf{~}$ & $\mathbf{3 0 0} \mathbf{~}$ & $\mathbf{4 0 0} \mathbf{~}$ & $\mathbf{5 0 0} \mathbf{~ m}$ & $\mathbf{6 0 0} \mathbf{m}$ & $\mathbf{7 0 0} \mathbf{~ m}$ & $\mathbf{8 0 0} \mathbf{~ m}$ & $\mathbf{9 0 0} \mathbf{~ m}$ & $\mathbf{1 0 0 0} \mathbf{~ m}$ \\
\hline Rutting & Normal road & 80 & 74 & 78 & 77 & 80 & 79 & 71 & 78 & 77 & 78 \\
depth index & Testing road & 82 & 79 & 81 & 84 & 83 & 80 & 85 & 87 & 80 & 79 \\
\hline Riding & Normal road & 91 & 90 & 95 & 92 & 92 & 91 & 94 & 95 & 91 & 94 \\
quality index & Testing road & 95 & 93 & 92 & 92 & 93 & 93 & 94 & 94 & 95 & 93 \\
\hline
\end{tabular}

As previously mentioned in Section 3, OSSC filler can improve the high-temperature stability of asphalt materials, which may be also reflected in asphalt pavement. It can be observed from Table 9 that most rutting depth index results of testing road are graded as "good", whereas most rutting depth index results of normal road are graded as "medium". As for riding quality index, there is a rough consistence between normal and testing roads, and their riding quality indices are basically graded as "very good". Overall, the testing asphalt road containing OSSC filler has a slightly better rutting depth index than the normal asphalt road.

The cylindrical cored specimens were used for low-temperature tests, and the indirect tensile strength test was conducted for evaluation of resisting cracks [35]. In this paper, the test temperature was $-10^{\circ} \mathrm{C}$, and the speed of applied loading was $1 \mathrm{~mm} / \mathrm{min}$ until failure occurred. Through the failure load and the dimensions of specimen, indirect tensile strength (ITS) is defined by

$$
\operatorname{ITS}=(2 \times P) /(\pi \times D \times h),
$$

where ITS is indirect tensile strength, $P$ is the failure load, $D$ is the diameter of the specimen, and $h$ is the height of the specimen.

Figure 10 demonstrates the indirect tensile strength test. According to the test results, the calculated indirect tensile strengths of the specimens cored from normal and testing roads are similar to each other, in which the mean values of indirect tensile strength for three replicate specimens are $2.883 \mathrm{MPa}$ and $2.954 \mathrm{MPa}$ for normal and testing asphalt pavements, respectively. In addition, the pavement damage detection was conducted for the normal and testing roads shown in Figure 8. According to JTG H20-2007 [34], due to limited conditions, a manual field investigation method was adopted to record the pavement damage for all lanes. The field investigation of pavement damage includes pavement crack, block cracks, longitudinal cracks, and transverse cracks. It can be seen that there are not too many significant cracks occurred on these two roads. These observations indicate that asphalt pavement containing OSSC filler can meet the low-temperature requirement, and OSSC filler is effective for asphalt pavement in terms of low-temperature cracking resistance. 


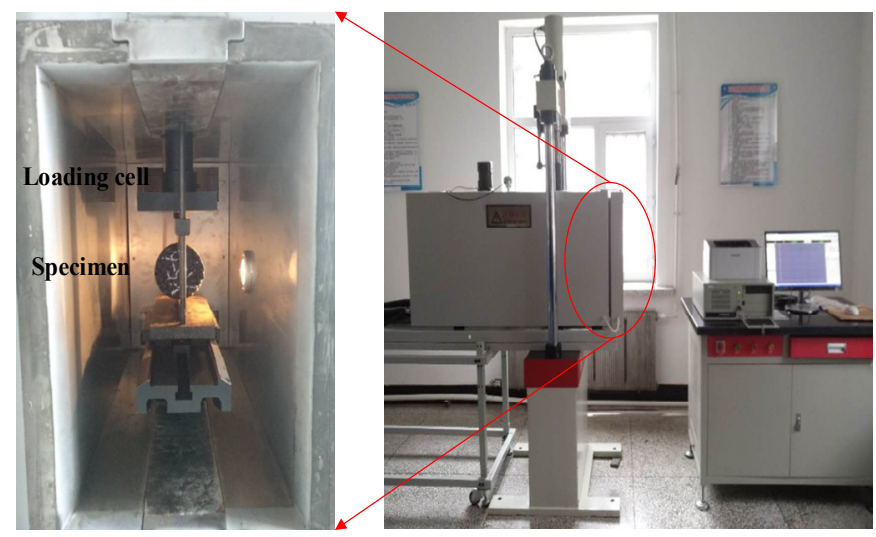

Figure 10. Indirect tensile strength test.

\section{Conclusions}

In this paper, waste OSA was recycled to partially replace traditional mineral powder for asphalt materials. The high- and low-temperature properties of asphalt materials were evaluated based on laboratory experiments and testing roads. The following conclusions can be drawn:

(1) Adding OSA may lead asphalt to a softer consistency and less temperature susceptibility in terms of penetration and softening point test results. The optimum OSA/MP ratio of asphalt mastics can be recommended as approximately $20 \%$.

(2) OSA can improve the rheological properties of asphalt materials and enhance the rutting resistance of asphalt mastics. As for the intermediate-temperature properties, the effect of OSA on asphalt mastics is negligible. Meanwhile, the effect of OSA on the low-temperature properties of asphalt mastics is insignificant by comparison.

(3) Based on the results of one-way ANOVA for high- and low-temperature properties of asphalt mixtures, it can be concluded that PPOSA has insignificant influence on the dynamic stability of asphalt mixture for AC and ATB, while SROSFA and OSSC present significant influences on the asphalt mixtures for AC, SMA, and ATB. However, PPOSA, SROSFA, and OSSC present insignificant influences on the low-temperature cracking resistance of the asphalt mixture.

(4) Based on testing roads, it can be proved that the sustainable asphalt materials containing OSA have better high-temperature stability and rutting resistance and also fulfill the requirements of low-temperature cracking resistance. Thus, the addition of OSA filler is beneficial for asphalt pavement in seasonal frozen regions.

Author Contributions: Y.C. built the overall framework; W.W. designed the experiments and wrote the paper; G.T. assisted the group in overall research method, revised the manuscript and corrected grammar; C.S. prepared the samples and performed the experiments. All authors discussed and contributed to the manuscript.

Funding: This work was supported by the National Natural Science Foundation of China (Grant No. 51678271) and the Science Technology Development Program of Jilin Province (20160204008SF).

Acknowledgments: The authors appreciate anonymous reviewers for their constructive suggestions and comments to improve the quality of the paper.

Conflicts of Interest: The authors declare no conflict of interest.

\section{References}

1. Liu, Z.; Dong, Q.; Ye, S.; Zhu, J.; Guo, W.; Li, D.; Liu, R.; Zhang, H.; Du, J. The Situation of Oil Shale Resources in China. J. Jilin Univ. 2006, 36, 870-876. (In Chinese)

2. Jiang, X.; Han, X.; Cui, Z. New technology for the comprehensive utilization of Chinese oil shale resources. Energy 2007, 32, 772-777. [CrossRef]

3. Singh, M.; Siddique, R. Effect of coal bottom ash as partial replacement of sand on workability and strength properties of concrete. J. Clean. Prod. 2016, 72, 20-32. [CrossRef] 
4. Zhen, C.; Jiang, S.L.; Chi, S.P. Combined use of sewage sludge ash and recycled glass cullet for the production of concrete blocks. J. Clean. Prod. 2018, 171, 1447-1459.

5. Hanni, R. Energy and valuable material by-product from firing Estonian oil shale. Waste Manag. 1996, 16, 97-99. [CrossRef]

6. Smadi, M.M.; Haddad, R.H. The use of oil shale ash in Portland cement concrete. Cem. Concr. Compos. 2003, 25, 43-50. [CrossRef]

7. Zhang, Y.; Leng, Z.; Zou, F.; Wang, L.; Chen, S.; Tsang, D. Synthesis of zeolite A using sewage sludge ash for application in warm mix asphalt. J. Clean. Prod. 2018, 172, 686-695. [CrossRef]

8. Arabani, M.; Tahami, S.A. Assessment of mechanical properties of rice husk ash modified asphalt mixture. Constr. Build. Mater. 2017, 149, 350-358. [CrossRef]

9. Jeffry, S.N.A.; Jaya, R.P.; Hassan, N.A.; Yaacob, H.; Satar, M. Mechanical performance of asphalt mixture containing nano-charcoal coconut shell ash. Constr. Build. Mater. 2018, 173, 40-48. [CrossRef]

10. Liu, H.; Fu, L.; Jiao, Y.; Tao, J.; Wang, X. Short-Term Aging Effect on Properties of Sustainable Pavement Asphalts Modified by Waste Rubber and Diatomite. Sustainability 2017, 9, 996.

11. Cheng, Y.; Zhu, C.; Tao, J.; Jiao, Y.; Yu, D.; Xiao, B. Effects of Diatomite-Limestone Powder Ratio on Mechanical and Anti-Deformation Properties of Sustainable Sand Asphalt Composite. Sustainability 2018, 10, 808. [CrossRef]

12. Guo, Q.; Li, L.; Cheng, Y.; Jiao, Y.; Xu, C. Laboratory evaluation on performance of diatomite and glass fiber compound modified asphalt mixture. Mater. Des. 2015, 66, 51-59. [CrossRef]

13. Ghuzlan, K.; Al-Khateeb, G.; Damrah, A.A. Using oil shale ash waste as a modifier for asphalt binders. J. Mater. Cycles Waste Manag. 2013, 15, 522-529. [CrossRef]

14. Al-Masaeid, H.; Khedaywi, T.; Smadi, M. Properties of Asphalt-Oil Shale Ash Bituminous Mixtures under Normal and Freeze-Thaw Conditions. J. Transp. Res. Board 1989, 1228, 54-62.

15. Asi, I.; Assa'Ad, A. Effect of Jordanian Oil Shale Fly Ash on Asphalt Mixes. Mater. Civil Eng. 2005, 17, 553-559. [CrossRef]

16. Wahhab, A.A.; Hussein, I.A.; Parvez, M.A.; Shawabkeh, R.A. Use of modified oil fly ash to enhance asphalt concrete performance. Mater. Struct. 2015, 48, 3231-3240. [CrossRef]

17. Azzam, M.O.J.; Al-Ghazawi, Z. Evaluation of incorporating oil shale filler aggregate into hot mix asphalt using Superpave mix design. Constr. Build. Mater. 2015, 101, 359-379. [CrossRef]

18. Azzam, M.O.J.; Al-Ghazawi, Z.; Al-Otoom, A. Incorporation of Jordanian oil shale in hot mix asphalt. J. Clean. Prod. 2015, 112, 2259-2277. [CrossRef]

19. Han, X.; Jiang, X.; Cui, Z. Change of Pore Structure of Oil Shale Particles during Combustion. 2. Pore Structure of Oil Shale Ash. Energy Fuels 2008, 22, 972-975. [CrossRef]

20. ASTM D5-2006. Standard Test Method for Penetration of Bituminous Materials; American Society for Testing and Materials: West Conshohocken, PA, USA, 2006.

21. ASTM D36-2006. Standard Test Method for Softening Point of Bitument (Ring and Ball Apparatus); American Society for Testing and Materials: West Conshohocken, PA, USA, 2006.

22. Yan, K.; He, W.; Chen, M.; Liu, W. Laboratory investigation of waste tire rubber and amorphous poly alpha olefin modified asphalt. Constr. Build. Mater. 2016, 129, 256-265. [CrossRef]

23. ASTM D113-2007. Standard Test Method for Ductility of Bituminous Materials; American Society for Testing and Materials: West Conshohocken, PA, USA, 2007.

24. Tan, Y.; Li, Z.; Zhang, X.; Dong, Z. Research on highand low-temperature properties of asphalt-mineral filler mastic. J. Mater. Civ. Eng. 2010, 22, 811-819.

25. ASTM D7175-2015. Standard Test Method for Determining the Rheological Properties of Asphalt Binder Using a Dynamic Shear Rheometer; American Society for Testing and Materials: West Conshohocken, PA, USA, 2015.

26. Behnood, A.; Olek, J. Rheological properties of asphalt binders modified with styrene-butadiene-styrene (SBS), ground tire rubber (GTR), or polyphosphoric acid (PPA). Constr. Build. Mater. 2017, 151, 464-478. [CrossRef]

27. Behnood, A.; Shah, A.; Mcdaniel, R.S.; Beeson, M.; Olek, J. High-Temperature Properties of Asphalt Binders: Comparison of Multiple Stress Creep Recovery and Performance Grading Systems. J. Transp. Res. Board 2016, 2574, 131-143. [CrossRef]

28. AASHTO T313-2009. Standard Method of Test for Determining the Flexural Creep Stiffness of Asphalt Binder Using the Bending Beam Rheometer; American Society for Testing and Materials: West Conshohocken, PA, USA, 2009. 
29. Tan, Y.; Lei, Z.; Zhang, X. Investigation of low-temperature properties of diatomite-modified asphalt mixtures. Constr. Build. Mater. 2012, 36, 787-795.

30. Moretti, L.; Mandrone, V.; D'Andrea, A.; Caro, S. Comparative "from Cradle to Gate" Life Cycle Assessments of Hot Mix Asphalt (HMA) Materials. Sustainability 2017, 9, 400. [CrossRef]

31. Chen, H.; Xu, Q.; Chen, S.; Zhang, Z. Evaluation and design of fiber-reinforced asphalt mixtures. Mater. Des. 2009, 30, 2595-2603. [CrossRef]

32. JTG E20-2011. Standard Test Methods of Bitumen and Bituminous Mixtures for Highway Engineering; Ministry of Transport of the People's Republic of China: Beijing, China, 2011. (In Chinese)

33. Ma, T.; Wang, H.; Huang, X.; Wang, Z.; Xiao, F. Laboratory performance characteristics of high modulus asphalt mixture with high-content RAP. Constr. Build. Mater. 2015, 101, 975-982. [CrossRef]

34. JTG H20-2007. Highway Performance Assessment Standard; Ministry of Transport of the People's Republic of China: Beijing, China, 2007. (In Chinese)

35. Navarro, F.M.; Gámez, M.C.R. Influence of Crumb Rubber on the Indirect Tensile Strength and Stiffness Modulus of Hot Bituminous Mixes. J. Mater. Civ. Eng. 2012, 24, 715-724. [CrossRef]

(C) 2018 by the authors. Licensee MDPI, Basel, Switzerland. This article is an open access article distributed under the terms and conditions of the Creative Commons Attribution (CC BY) license (http://creativecommons.org/licenses/by/4.0/). 